\title{
Equines as Tools Vs Partners: A Critical Look at the Uses and Beliefs Surrounding Horses in Equine Therapies and Argument for Mechanical Horses
}

\author{
Kieson $\mathrm{E}$ and Abramson CI \\ Oklahoma State University, Laboratory of Comparative Psychology and Behavioral Biology, OSU, Stillwater, OK, \\ USA
}

${ }^{*}$ Corresponding author: Abramson CI, Oklahoma State University, Laboratory of Comparative Psychology and Behavioral Biology, 111 N. Murray, OSU, Stillwater, OK, USA 74078, Tel: (405) 744-7591, E-mail: charles. abramson@okstate.edu

Citation: Kieson E, Abramson CI (2017) Equines as Tools Vs Partners: A Critical Look at the Uses and Beliefs Surrounding Horses in Equine Therapies and Argument for Mechanical Horses. J Vet Sci Anim Husb 5(1): 107. doi: 10.15744/2348-9790.5.107

Received Date: November 11, 2016 Accepted Date: February 25, 2017 Published Date: February 28, 2017

\begin{abstract}
Horses have their own unique status as therapy animals due to their function in both physical and psychotherapies. Current models of Equine Assisted Activities and Therapies (EAAT) utilize horses for a range of physical, psychological and learning therapies to benefit humans, often referring to horses as therapeutic "partners". To fulfill certification requirements for existing models of EAAT, practitioners are required to study equine behavior through the belief systems currently modeled in the natural horsemanship community. Despite requiring knowledge in horse behavior, studies and anecdotal evidence suggests that horses used in EAAT commonly display confusion or escape behaviors, "burn out" and/or display signs of depression. These behaviors could be a result of contradictions in the interpretation of equine behavior within the natural horsemanship practices or a lack of understanding and utilization of equine learning theory within the context of EAAT. This study looked at the use of horses for physical and psychotherapy in four leading models of EAAT: the Professional Association of Therapeutic Horsemanship (PATH), Equine Assisted Growth and Learning Association (EAGALA), Natural Lifemanship (NL) and Eponaquest. The study found that, although interpretation of horse behavior is considered critical in each model, there are no standards for understanding equine behavioral psychology within or between the models. Furthermore, the use of horses in physical therapy or as a rhythmic tool for psychotherapy suggests that there may be cause to develop mechanical horses that can produce the same physical benefits as horseback riding.
\end{abstract}

Keywords: Equine; Behavior; Assisted; Therapy; Welfare

\section{Introduction}

Horses are unique in their role as therapy animals due to their function in both physical and psychotherapies. As versatile therapy animals, horses are used for riding, interactive ground work, grooming and touch therapy, as well as being used as observational tools for trauma patients. Over the course of the last few decades, organizations and groups have developed standardized systems, known as models, for using horses in their programs. Table 1 provides examples of how these models are designed to provide physical, intellectual, educational, emotional, and psychological benefits to people and Table 1A clarifies the terminology used in the industry with regards to the uses of equines in different therapeutic techniques. As physical therapy animals, they provide benefits known as hippotherapy which provides bilateral rhythmic stimulation to the rider and helps simulate the same motion in the pelvis as walking [1] and has shown to improve strength and mobility in the elderly [2,3] and improved physical health in individuals with autism [4], intellectual disabilities [5], neuromuscular disorders [6], and children with cerebral palsy [79]. Therapeutic riding, where an individual finds physical, emotional, or psychotherapy through equitation has been shown to improve self-regulation in individuals with autism spectrum disorder [10]. It is unclear, however, if the self-regulation is a result of physical motion or interaction with the horse.

Recent research in Equine Assisted Therapies (EAT), including Equine Assisted Psychotherapy (EAP), shows that it improves trust and secure attachments in traumatized youth [11], boosts cognitive and relationship skills in children with autism [12], improves psychiatric treatment in trauma patients [13], and increases in mental wellbeing of individuals with other psychological or neurological disorders $[13,14]$. In psychotherapy models, horses interact with humans on the ground and there are often no 
riding elements. Under these circumstances, there may be a variety of options for interactions between human and horse that could include grooming, leading, or lunging the horse or simply observing horses.

\begin{tabular}{|c|c|c|c|c|}
\hline Type of EAAT & PATH & EAGALA & $\mathrm{NL}$ & Eponaquest \\
\hline Hippotherapy & $\mathrm{X}$ & & & \\
\hline Therapeutic Horsemanship & $\mathrm{X}$ & $\mathrm{X}$ & $\mathrm{X}$ & $\mathrm{X}$ \\
\hline Therapeutic Riding & $\mathrm{X}$ & & $\mathrm{X}$ & $\mathrm{X}$ \\
\hline Equine Assisted Therapy (EAT) & $\mathrm{X}$ & $\mathrm{X}$ & $\mathrm{X}$ & $\mathrm{X}$ \\
\hline Equine Assisted Psychotherapy (EAP) & $\mathrm{X}$ & $\mathrm{X}$ & $\mathrm{X}$ & $\mathrm{X}$ \\
\hline Equine Facilitated Learning (EFL) & $\mathrm{X}$ & $\mathrm{X}$ & $\mathrm{X}$ & $\mathrm{X}$ \\
\hline
\end{tabular}

Table 1: Types of Therapies Used in Each Model with Associated Terminology

\begin{tabular}{|c|c|}
\hline Term & Definition \\
\hline Hippotherapy & Physical, occupational or speech therapy treatment strategy that utilizes equine movement. \\
\hline Therapeutic Horsemanship & $\begin{array}{l}\text { Equine activities organized and taught by knowledgeable and skilled instructors to people } \\
\text { with disabilities or diverse needs. Equestrian skills are part of this program }\end{array}$ \\
\hline Therapeutic Riding & Mounted activities including traditional riding disciplines or adapted riding activities. \\
\hline Equine Assisted Therapy (EAT) & Treatment that incorporates equine activities and/or the equine environment \\
\hline $\begin{array}{l}\text { Equine Assisted Psychotherapy } \\
\text { (EAP) }\end{array}$ & $\begin{array}{l}\text { Experiential psychotherapy that includes equines and may include a range of equine activi- } \\
\text { ties including riding, driving, grooming, or ground work. EFP is facilitated by a mental } \\
\text { health professional }\end{array}$ \\
\hline $\begin{array}{l}\text { Equine Facilitated Learning } \\
\text { (EFL) }\end{array}$ & $\begin{array}{l}\text { Education that incorporates the human-equine interaction and the goals may be self- } \\
\text { improvement, social, or educational }\end{array}$ \\
\hline
\end{tabular}

Table 1A: Associated Terminology used in Therapies [30]

Horses used in Equine Facilitated Learning (EFL) are handled much in the same way as they are in EAT, but with the focus on improving learning or social functions using horses and horsemanship. Most of the available research in this category focuses primarily on the client/human component and the benefits to humans with little research looking at equine behavior in the therapeutic context. Since there is no current standardized system of evaluating horse behavior in this environment, therapists and equine specialists working in EAT use subjective interpretation when observing equine behavior. This may contribute to difficulties in researching horse behavior in the therapeutic environment $[15,16]$.

To identify possible problems associated with studying equine behavior in therapy, this study looked at four different EAAT models, Professional Association of Therapeutic Horsemanship (PATH), Equine Assisted Growth and Learning Association (EAGALA), Natural Lifemanship (NL) and Eponaquest and how each described horses in their literature and how each used the horses in practice. The rationale behind the selection of these four models was based on the size of the organization and the number of states or countries in which the model is used. These four were selected due to their wide use internationally and nationally within the United States.

\section{Materials and Methods}

Models and Methods for EAAT in PATH, EAGALA, and NL were evaluated based on training manuals and training workshops sponsored by the programs. The model and methods for Eponaquest were collected via publicly available information. All the models were first assessed and broken down into their use of horses, basic principles and view of horses, and requirements for professional interactions for the model (Table 1 and 2). Physical use of horses in the model indicates how the horse is physically handled during each session which incorporates any use of positive or negative reinforcement or punishment, making it a good indicator of how learning theory is applied within the model. The overall principles and view of horses looks at how the organization or model perceives horses within this context and whether they describe horses as partners in the therapeutic process or if they are objects. With regards to professional requirements, the study considered the background of equine professionals and therapists and their knowledge about equine behavior as well as their ability to accurately interpret horse behavior during interaction with clients.

Once the principles and theoretical backgrounds for each model were assessed, the practices of the methods of EAAT within each model were then evaluated based on the criteria set forth for evaluating how horses are used in the model (Table 3). By exploring the fundamental principles of each model, the study looked at how each model considered equine learning and equine behavior with regards to how they view the horse's role in therapy.

Three of the four evaluations were done using the training manuals in addition to publicly available information. The training manuals used for this study were acquired during training sessions specific to the models (PATH, EAGALA, and NL) and are not publicly available although overviews of models are available through each organization's website. Theories and practices of models were assessed for using horses as partners or tools based on criteria derived from research in equine learning theory, horse 
behavior, and equine ethology. These criteria were broken down into categories based on this research and are listed in Table 3. For methods to fit criteria for "Equines as Partners", the design of activities and perception of equine behavior aligned with current research in equine behavioral psychology within the context of human interaction. Methods used in models that did not align with current research in equine behavioral psychology or contradicted current literature, were evaluated based on the criteria listed in "Equines as Tools".

\begin{tabular}{|c|c|c|c|c|}
\hline Name & PATH & EAGALA & NL & Eponaquest \\
\hline Concept & $\begin{array}{l}\text { "Providing a culture of safety, } \\
\text { understanding, and ethical } \\
\text { treatment of humans and hors- } \\
\text { es engaged in equine-assisted } \\
\text { activities and therapies" }\end{array}$ & $\begin{array}{l}\text { "Respect and Honor the } \\
\text { value, dignity, safety, wel- } \\
\text { fare and best interests of } \\
\text { the clients and horses" }\end{array}$ & $\begin{array}{l}\text { "Building a functional } \\
\text { relationship with the horse } \\
\text { and transferring those skills } \\
\text { to people" }\end{array}$ & $\begin{array}{c}\text { "Horses are soulful animals } \\
\text { with whom we connect and } \\
\text { build relationships" }\end{array}$ \\
\hline Horse Interaction & $\begin{array}{l}\text { Mostly Ground Work } \\
\text { Riding is limited and highly } \\
\text { regulated }\end{array}$ & $\begin{array}{l}\text { Ground work Only } \\
\text { No Riding }\end{array}$ & $\begin{array}{l}\text { Ground Work } \\
\text { Riding (rider is given no } \\
\text { instructions) }\end{array}$ & $\begin{array}{l}\text { Mostly Ground Work } \\
\text { Limited Riding }\end{array}$ \\
\hline $\begin{array}{l}\text { Professionals } \\
\text { Involved }\end{array}$ & $\begin{array}{c}2 \text { - Therapist and Equine } \\
\text { Specialist }\end{array}$ & $\begin{array}{c}2 \text { - Therapist and Equine } \\
\text { Specialist }\end{array}$ & $\begin{array}{l}1 \text { - Therapist (although an } \\
\text { Equine Specialist is recom- } \\
\text { mended) }\end{array}$ & $\begin{array}{l}1 \text { - Therapist (although an } \\
\text { Equine Specialist is recom- } \\
\text { mended) }\end{array}$ \\
\hline
\end{tabular}

Table 2: Model Concepts, Use of Horses, and Professional Requirements [30-33]

\begin{tabular}{|l|l|}
\hline \multicolumn{1}{|c|}{ Criteria for “Equine as Partner" } & \multicolumn{1}{c|}{ Criteria for "Equine as Tool" } \\
\hline $\begin{array}{l}\text { - Equine behavior observed and evaluated in the con- } \\
\text { text of horse behavior with human }\end{array}$ & $\begin{array}{l}\text { - Equine behavior evaluated in the context of human behavior } \\
\text { (anthropomorphism) }\end{array}$ \\
- Equine welfare prioritized with human welfare & - Human welfare prioritized at expense of horse \\
- Client willingness to participate & - Client not willing to participate \\
- Horse allowed to respond/react & - No regards to horse psychology with regards to session \\
- Positive reinforcement prioritized & - Horse punished or manipulated in order to facilitate therapy \\
& session \\
& - Negative reinforcement \\
\hline
\end{tabular}

Table 3: List of Criteria for Categorization of Methods within Each Model

With regards to the human-equine interaction, the study considered how models looked at equine training versus equine learning. Equine learning uses positive reinforcement whereas equine training uses negative reinforcement [17]. In general, most equitation relies on negative reinforcement as a form of contact and training where pressure from the bit, legs, weight, or whip is added and then removed when the horse demonstrates the appropriate behavior. Positive reinforcement, on the other hand, relies on reward values usually in the form of novel food rewards or light stroking or scratching. Equine learning (via positive reinforcement) takes into account genetic predisposition and past experiences with environments, humans, and other horses [17]. Since EAAT promotes partnership instead of training, models that promote this concept need to incorporate the theories, practices, and principles of learning theory with regards to positive reinforcement and associative learning.

Criteria for classifying model methods as treating the horse as a "partner" were dependent upon the model's ability to recognize, assess, and respond to horse reactions in a way that is in line with equine learning theory and ethology (Table 3). Horses evaluate humans based on interaction and associations [18] and respond to people based on environmental context [19,20] which can indicate what they see as rewarding versus aversive [21]. Therefore, methods in each model were categorized in the "Equine as Partner" category needed to take into consideration the evaluation of horse behavior in the horse-client interaction. They also needed to prioritize horse welfare along with human welfare. In addition, since a client's willingness to participate can affect the horse's reaction [22], models were also assessed based on their view of a client's willingness to be a part of the session. Furthermore, methods were categorized as using horses as "partners" if the interaction between horse and human was beneficial (or at the very least neutral) to the horse and allowed for the horse to respond and react without interference. This is important because horses learn from humans using operant conditioning and their behavior is shaped through appropriate use of positive and negative reinforcement [23].

In learning theory, reinforcement refers to a method of feedback that leads to increased likelihood of a behavior being repeated. In equitation, positive reinforcement is the use of rewards such as treats and scratching and negative reinforcement refers to the removal of aversive stimuli such as pressure on the bit or from the legs. The idea of pressure and release in training horses is a negative reinforcement tool [24] and horses are traditionally trained with negative reinforcement [23]. Studies show that avoidance behaviors were greater with those trained with negative reinforcement and investigative behaviors were observed more in the positive reinforcement group [23]. Therefore, when considering the psychological wellness of the horse, practitioners need to assess behavioral cues of the horse and focus on both the lack of negative experiences in addition to the presence of positive ones [25]. Therefore, the last criteria for the partnership categorization were an evaluation of the prioritization of positive reinforcement over punishment or negative reinforcement. 
The criteria used for categorizing methods as "Equine as Tools" relied upon each model's perception of the horse, lack of adequate understanding of horse behavior, and primary use of negative reinforcement (Table 3). Understanding horse behavior is critical in evaluating their response to human interactions [23] especially in the context of equine ethology. The main criteria for evaluating a method in terms of equine tools focused on the model's use of anthropomorphism of the horse with little understanding of horse behavior and a prioritization of the evaluation of human behavior in that context. According to recent literature, a "tool" is not well defined. One definition, however, defines it as "the external employment of an unattached or manipulable object" to alter the condition of another object or organism [26]. In this case, the study evaluated how each model used horses as external objects that were manipulated for the facilitation of therapy. Additional criteria in this category included punishment or manipulation of the horse for the facilitation of the therapy session in addition to focus on negative reinforcement. This is especially important since horses trained with negative reinforcement display more behaviors associated with stress and a tense emotional state [27]. Since horses learn from humans and their environment [28], EAAT practitioners need to be aware of all the stimuli involved in the session as well as how each individual horse displays signs of stress and coping [29].

\section{Results}

\section{Equines as Partners}

Each model's theories, principles, and practices were evaluated based on the criteria established for treating each equine as a "partner" (Table 3). These criteria included whether equine behavior was observed and evaluated in the context of horse behavior with human, whether equine welfare was prioritized with human welfare, if the client demonstrated willingness to participate, if the session was beneficial or neutral to horse, if the horse could respond/react, and if positive reinforcement was prioritized. The following is a breakdown as to what was found with regards to each model.

Equines as Partners - Professional Association of Therapeutic Horsemanship (PATH): The evaluations for the use of equines as "partners" in PATH was based on the training and manual associated with the workshop in certifying individuals as equine specialists in mental health and learning [30]. According to the manual, the focus of EAAT in PATH is on respecting the rights and dignity of the client and horse with an emphasis on promoting equine well-being during and after the sessions. PATH further promotes the concept by stating that "equines are sentient beings, partners, and active facilitators" in the EAAT process [30]. The manual goes on to explain that, in the PATH model, equines function as partners and sessions must be mutually beneficial for all participants including equines and that "equines are not to be manipulated, scared or teased or used as a tool or props" [30]. Animal behavior is a key component of the PATH model with a focus on respect and admiration for the horse as a unique contributor to the session. The manual emphasizes this by stating "If we treat animals as expendable, or carry even the subtlest 'power over' mentality, our clients will inevitably assume this attitude themselves. For this reason we must be mindful as therapists about what we unconsciously convey through human verbal and nonverbal behavior about the care of others different from ourselves." [30]. It goes on to say "To conduct the most ethical work, we must know enough about animal behavior to be able to see the subtle signs of stress an animal may experience in doing this work. Also important to consider is the ability of the therapist to explain the behavior of the animal to the client" [30].

Equines as Partners - Equine Assisted Growth and Learning Association (EAGALA): The evaluation of the use of equines at "partners" within the Equine Assisted Growth and Learning Association (EAGALA) was based on the workshop and corresponding manual for teaching the fundamentals of the program [31]. According to the manual, the focus of the EAGALA model is on changing the behavior of the client to elicit changes in horse behavior by helping the client to become more aware of his or her behavior and how that affects the horse [31]. During the EAGALA sessions, the equine specialist is required to be present in order to focus on and interpret horse behavior and ensure the welfare of the horse in each session [31]. Furthermore, the EAGALA model emphasizes the process of interaction and the building of relationships between the human and equine, allowing the horse to be free (no restrictions or halters) and able to willingly display behavioral responses within the session and learn from its environment [31]. As a matter of looking at the horse as a "partner", the EAGALA model focuses on observing horse behavior and facilitates equine curiosity within the session [31].

Equines as Partners - Natural Lifemanship (NL): The evaluation of equines as "partners" for the Natural Lifemanship (NL) model was based on the manual for the model and the workshop associated with the fundamentals of the program [32]. According to the manual, the NL model is based on the idea that horses react to behaviors in the same way that humans react to behaviors [32]. The focus of the program is on building trust between horse and human with a large focus on the willingness of the client to work with the horse. The NL manual specifically states that "horses are not mirrors, they respond/react to us" [32].

Equines as Partners - Eponaquest: The evaluation of equines as "partners" for Eponaquest was based on publicly-available information [33]. Per the Eponaquest description of services and philosophies, the Eponaquest model is based on promoting the welfare of the horse with a large focus on building and establishing good relationship skills [33]. Publicly available information did not go into detail as to how this is accomplished.

\section{Equines as Tools}

In the same way that each model was evaluated for their use of horses as partners, each model's theories, principles, and practices 
were also evaluated based on the criteria established for treating each equine as a "tool" (Table 3). These criteria included whether equine behavior was evaluated based on horse ethology or in the context of human behavior (anthropomorphism), if human welfare was prioritized at the expense of the horse, and if the client was a willing participant in the sessions. Furthermore, the use of equines as "tools" in each model was also based on if the model showed no focus on horse psychology with regards to their use in sessions, if the horse was punished or manipulated to facilitate a therapy session, or if negative reinforcement was used.

Equines as Tools - Professional Association of Therapeutic Horsemanship (PATH): According to the PATH training manual for equine specialists in mental health and learning, the PATH model involves clients who do not willingly want to participate in sessions (often court-ordered therapy) and may ultimately create circumstances where negative reinforcement or punishment are used to move the horse [30]. The model also suggests that many sessions require the human to move the horse (potential use of negative reinforcement) as well as looking at the "reactions" of the horse based on these conditions [30].

Equines as Tools - Equine Assisted Growth and Learning Association (EAGALA): Per the workshop and fundamentals of EAGALA manual, horses in this model are used as metaphors and are not seen as horses. Specifically, clients or groups are told that the horse is a "metaphor" and not an actual animal [31]. Furthermore, the facilitators (therapist and equine professional) deliberately withhold knowledge of equine behavior and horsemanship skills from client. This is done with the intention of providing an atmosphere in which the client can act "normal" and engage in behaviors that he/she would demonstrate in other, non-equine environments. When the horse responds, the client is then asked to interpret horse "reactions" with regards to the metaphor of the session [31]. According to the EAGALA manual, the focus of the sessions is on humans learning about themselves as they interact/ move the horse and that horse behavior is only seen as a function of reaction to client(s) without accurate interpretation of the behavior within the context of equine ethology [31]. The EAGALA model uses the Socratic method of student self-learning with the horse so that horsemanship or knowledge of the horse is discouraged because it facilitates clients "bonding, communicating with, and loving horses" [31]. The client, not the equine professional, is encouraged to interpret horse behavior and trial new behaviors with the horse without any knowledge of horses or equine behavior. This could ultimately lead to increases in negative reinforcement or positive punishment [31].

Equines as Tools - Natural Lifemanship (NL): Within the NL model, clients use horses to recreate human relationships and are encouraged to treat horses the same way they treat people [32] which can result in extreme uses of positive punishment or negative reinforcement. The model also utilizes a form of therapeutic riding called "rhythmic riding" which is designed to assist in selfregulation and only used when it's more effective than ground work [32]. Although bilateral rhythmic stimulation has been shown to be effective therapy under certain conditions, the use of horses in NL for riding does not involve instructions or assistance by horse professionals and, instead the horse is used as a regulation tool and often used prior to ground work if client has problems self-regulating [32].

Without the use of proper instruction or knowledge of horse behavior and equipment, such riding could result in unnecessary pressures from the rider and tack and result in unexpected circumstances where the horse experiences aversive stimulation from which it cannot escape. When ground work is incorporated into the NL model, the horse is used as a tool to increase stress in the client to facilitate client reactions [32]. The purpose of this is to facilitate sessions where the focus is on "controlling the horse" so the client can learn to control their "environment". During the session, the clients are allowed to express frustrations with the horse if the horse does not respond as desired [32]. The purpose of this practice is to allow the therapists to observe the client's ability to handle stress [32] (potentially at the expense of the horse).

The NL model also teaches natural horsemanship to the clients to "teach appropriate behaviors" to the horses through negative reinforcement and asks clients to then anthropomorphize any resulting behavior [32]. The interaction of the client with the horse is based on the concept of "who moves whose feet" with the only "reward" to the horse being the release of pressure [32]. If the horse ignores the "pressure" (which could be physical, verbal, behavioral, etc.), the client is told to increase the pressure [32]. The key ideas within the NL model with regards to this type of session are: "They ignore, we increase pressure", "They resist, we maintain/keep it the same", and "They attempt to comply or cooperate, we release" [32]. The basis for NL is to use horses to help with trauma, especially in children and one of the main focuses of the model states "Suggest, Ask, Tell, Insist" in order to teach children how to evoke "I mean what I say" when getting the horse's "attention" through pressure as a "first step in relationship building" [32]. Furthermore, the NL model states that when horses are "attached", the horse is responding by moving (using negative reinforcement) and is "disengaged" when it stops moving or stops responding to pressure [32].

Equines as Tools - Eponaquest: In the Eponaquest model, horse social behavior is used as a direct metaphor for human social behavior (use of anthropomorphism). Furthermore, the Eponaquest model teaches "strategies" for handling horses which may include the use of negative reinforcement or positive punishment [33].

\section{Discussion}

Equine learning requires consistency in operant conditioning and behavioral shaping under low-stress conditions to produce consistent and predictable behavioral results [1-7]. If equine specialists and EAAT practitioners have varied backgrounds in equine behavior, equine learning, or training techniques, such inconsistencies may result in varied responses to horses' behavior 
and interpretations of that behavior. The evaluations suggest that possible explanations for equine "burn out", or unexplained behavioral changes, may result from a combination of inconsistencies in interpretations of equine behavior both within and across models as well as from excessive use of negative reinforcement. The models have broad definitions and varied requirements for understanding equine behavior. Furthermore, equine specialists within each model may vary greatly in their understanding and interpretation of horse behavior.

The use of equines for physical therapy combined with inconsistencies in the interpretation of equine behavior suggests there is a need to develop more physiologically accurate mechanical horses. The Ridemaster by Racewood (http://www.racewood. com/ridemaster-pro.php) and the Equicizer (http://equicizer.com/?gclid=CPDEirbbqtECFaoW0wodJ10L-Q) are available for purchase and may provide adequate therapeutic benefits equal to that of a live horse. If proven to be of equal value, these would allow for clients to benefit from the movement of riding while simultaneously gaining more control over their bodies which ultimately results in greater consistency in equine interactions and less confusion behavior in the horse. Inconsistencies in rider movements combined with inaccuracies in professional assessment of equine behavior may be to blame for some of the behavioral inconsistencies reported in the EAAT industry. Anecdotally reported as "burn out", some EAAT horses gradually express behaviors that ultimately prevent them from being used in therapy. There are currently no standardized evaluations of horse behavior in equine therapy [15] so interpretation of changes in equine behavior during and after therapy sessions is dependent upon the facility and equine professional. All four EAAT models relied on self-reporting for hours or years of experience as a means of establishing a solid foundation and understanding of horse behavior which leads to inconsistences in interpretation and interventions with the therapy equine within and between models.

Furthermore, client EAAT sessions within the models tend to focus more on the physical interaction with the horse rather than accurate interpretation of equine behavior in this context. This suggests that any confusion behavior expressed by the horse may be misinterpreted by the equine professional. With regards to human interactions (riding as well as groundwork), horses can differentiate between riders and may experience different stress levels [34] which may result from irregular pressures on the horse from the rider [35]. These pressures, however, stabilize over time as the rider improves [35] and can better regulate body position and consistent cues. Since riding style and management conditions can affect behavior and indicate equine psychological welfare [36], the EAAT industry would benefit from a mechanical horse that can simulate the bilateral rhythmic movement of the horse. Since this type of movement has shown to be beneficial to the elderly and injured individuals [37,38], it may be useful to develop a model of mechanical horse that would duplicate the movement and allow for practitioners to isolate physical therapy from psychotherapy. An isolated physiologically accurate mechanical horse would allow clients to develop the stability and strength needed to give the horse consistent cues in the saddle, potentially resulting in less confusion, or "burn out", behavior in the therapy horse. Combined with more standardized interpretations of equine behavioral psychology in the context of EAAT, this would likely result in improved welfare for the horse and potentially improved results from all aspects of equine therapy. More research is needed, however, to determine the role of a live horse in hippotherapy and the role of a mechanical horse in EAAT.

\section{Conclusion}

The results of this study suggest that there is a need for further research into more accurate interpretations of equine behavior within the horse-human interaction, especially with regards to EAAT. Such research would benefit the equitation community at large and promote greater horse psychological welfare. With regards to EAAT, a better understanding of equine behavioral psychology would improve existing models by creating mutually beneficial relationships between both human and horse. Since many equine therapeutic practitioners use these models to help their clients practice relationship skills, this could potentially result in better therapeutic results by developing better empathy, patience, and perspective skills.

\section{References}

1. Garner B, Rigby BR (2015) Human pelvis motions when walking and when riding a therapeutic horse. Hum Mov Sci 39: 121-37.

2. de Araújo TB, de Oliveira RJ, Martins WR, de Moura Pereira M, Copetti F, et al. (2013) Effects of hippotherapy on mobility, strength and balance in elderly. Arch Gerontol Geriatr 56: 478-81.

3. Kim SG, Lee JH (2015) The effects of horse riding simulation exercise on muscle activation and limits of stability in the elderly. Arch Gerontol Geriatr 60: 62-5.

4. Jenkins SR, Digennaro Reed FD (2013) An experimental analysis of the effects of therapeutic horseback riding on the behavior of children with autism. Res Autism Spectr Disord 7: 721-40.

5. Giagazoglou P, Arabatzi F, Dipla K, Liga M, Kellis E (2012) Effect of a hippotherapy intervention program on static balance and strength in adolescents with intellectual disabilities. Res Dev Disabil 33: 2265-70.

6. Heine B (1997) Hippotherapy. A mulitsystem approach to the treatment of neuromuscular disorders. Aust Physiother 43: 145-9.

7. Shurtleff TL, Standeven JW, Engsberg JR (2009) Changes in Dynamic Trunk/Head Stability and Functional Reach After Hippotherapy. Arch Phys Med Rehabil 90: 1185-95.

8. Kwon JY, Chang HJ, Lee JY, Ha Y, Lee PK, et al. (2011) Effects of hippotherapy on gait parameters in children with bilateral spastic cerebral palsy. Arch Phys Med Rehabil 92: 774-9.

9. McGibbon NH, Benda W, Duncan BR, Silkwood-Sherer D (2009) Immediate and Long-Term Effects of Hippotherapy on Symmetry of Adductor Muscle Activity and Functional Ability in Children With Spastic Cerebral Palsy. Arch Phys Med Rehabil 90: 966-74. 
10. Gabriels RL, Agnew J, Holt KD, Shoffner A, Zhaoxing P, et al. (2012) Pilot study measuring the effects of therapeutic horseback riding on school-age children and adolescents with autism spectrum disorders. Res Autism Spectr Disord 6: 578-88.

11. Balluerka N, Muela A, Amiano N, Caldentey M (2014) Influence of animal-assisted therapy (AAT) on the attachment representations of youth in residential care. Child Youth Serv Rev 42: 103-9.

12. Hameury L, Delavous P, Teste B, Leroy C, Gaboriau JC, et al. (2010) Équithérapie Et Autisme. Ann Med Psychol 168: 655-9.

13. Nurenberg JR, Schleifer SJ (2011) Equine assisted therapy for patients with severe chronic psychiatric disorders. Eur Psychiatry $26: 1325$.

14. Muñoz Lasa S, Máximo Bocanegra N, Valero Alcaide R, Atín Arratibel M, Varela Donoso E, et al. (2013) Animal assisted interventions in neurorehabilitation: A review of the most recent literature. Neurologia 30: 1-7.

15. Anderson MK, Friend TH, Evans JW, Bushong DM (1999) Behavioral assessment of horses in therapeutic riding programs. Appl Anim Behav Sci 63: 11-24.

16. Pauw J (2000) Therapeutic Horseback Riding Studies: Problems Experienced by Researchers. Physiotherapy 86: 523-7.

17. Cooper JJ. (2007) Equine learning behaviour: common knowledge and systematic research. Behav Processes 76: 24-60.

18. Baragli P, Mariti C, Petri L, De Giorgio F, Sighieri C (2011) Does attention make the difference? Horses' response to human stimulus after 2 different training strategies. J Vet Behav Clin Appl Res 6: 31-8.

19. Baragli P, Gazzano A, Martelli F, Sighieri C (2009) How Do Horses Appraise Humans' Actions? A Brief Note over a Practical Way to Assess Stimulus Perception. J Equine Vet Sci 29: 739-42.

20. Birke L, Hockenhull J, Creighton E, Pinno L, Mee J, et al. (2011) Horses' responses to variation in human approach. Appl Anim Behav Sci 34 : 56-63.

21. Spruijt BM, van den Bos R, Pijlman FT (2001) A concept of welfare based on reward evaluating mechanisms in the brain: anticipatory behaviour as an indicator for the state of reward systems. Appl Anim Behav Sci 72: 145-71.

22. Cbamove AS, Crawley-hartrick O, Stafford KJ (2002) Horse reactions to human attitudes and behavior. J Anthrozoos 15: 323-32.

23. Bierke CM, Meinen RH, Wilkens EE, Leponiemi M, Hiney KM (2013) A comparison of negative and positive reinforcement in naïve horses. J Equine Vet Sci 33: 397.

24. Ahrendt LP, Labouriau R, Malmkvist J, Nicol CJ, Christensen JW (2015) Development of a standard test to assess negative reinforcement learning in horses. Appl Anim Behav Sci 169: 38-42.

25. Boissy A1, Manteuffel G, Jensen MB, Moe RO, Spruijt B, et al. (2007) Assessment of positive emotions in animals to improve their welfare. Physiol Behav 92: 375-97.

26. Crain BJ, Giray T, Abramson CI (2013) A tool for every job: Assessing the need for universal definition of tool use. Int J Comparative Psychol 26: 281-303.

27. Briefer Freymond S, Briefer EF, Zollinger A, Gindrat-von Allmen Y, Wyss C, et al. (2014) Behaviour of horses in a judgment bias test associated with positive or negative reinforcement. Appl Anim Behav Sci 158: 34-45.

28. Broom DM (2010) Cognitive Ability and Awareness in Domestic Animals and Decision About Obligations to Animals. Appl Anim Behav Sci 126: 1-11.

29. Budzyńska M (2014) Stress reactivity and coping in horse adaptation to environment. J Equine Vet Sci 34: 935-41.

30. Path International (2015) Professional Association of Therapeutic Horsemanship International Student Manual: Equine Specialist in Mental Health and Leaning Workshop, USA.

31. Equine Assisted Growth and Learning Association (2012) Fundamentals of EAGALA Model of Practice: Equine Assisted Psychotherapy Certification Program ( $7^{\text {th }}$ Edn) EAGALA. Santaquin, UT, USA.

32. Jobe, Tim D, Shultz-Jobe, Bettina N (2013) Natural Lifemanship: Trauma Focused Equine Assisted Psychotherapy (TF-EAP), USA.

33. Eponaquest (2016) Eponaquest Worldwide, USA.

34. Fazio E, Medica P, Cravana C, Ferlazzo A (2013) Hypothalamic-pituitary-adrenal axis responses of horses to therapeutic riding program: Effects of different riders. Physiol Behav 118: 138-43.

35. Janura M, Peham C, Dvorakova T, Elfmark M (2009) An assessment of the pressure distribution exerted by a rider on the back of a horse during hippotherapy. Hum Mov Sci 28: 387-93.

36. Normando S, Meers L, Samuels WE, Faustini M, Ödberg FO (2011) Variables affecting the prevalence of behavioural problems in horses. Can riding style and other management factors be significant? Appl Anim Behav Sci 133: 186-98.

37. Kubota M, Nagasaki M, Tokudome M, Shinomiya Y, Ozawa T, et al. (2006) Mechanical horseback riding improves insulin sensitivity in elder diabetic patients. Diabetes Res Clin Pract 71: 124-30.

38. Lechner HE, Kakebeeke TH, Hegemann D, Baumberger M (2007) The Effect of Hippotherapy on Spasticity and on Mental Well-Being of Persons With Spinal Cord Injury. Arch Phys Med Rehabil 88: 1241-8.

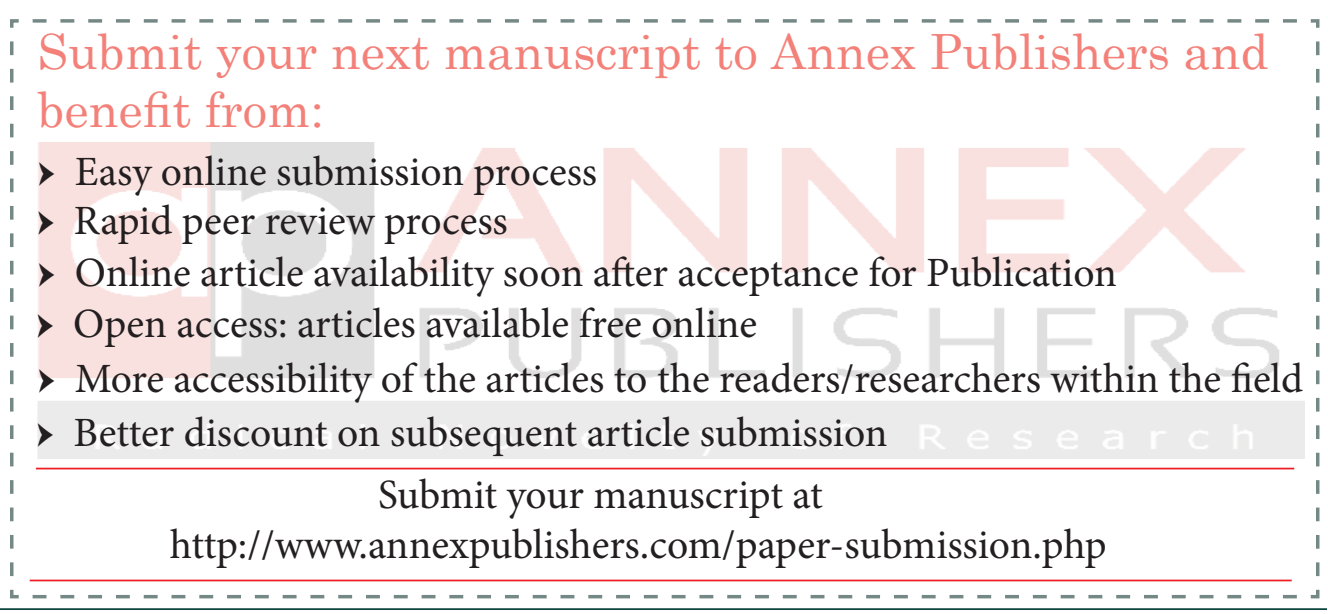

